\title{
Ecosystem Service Supply and Vulnerability to Global Change in Europe
}

Dagmar Schröter, ${ }^{1,2 *}$ Wolfgang Cramer, ${ }^{1}$ Rik Leemans, ${ }^{3}$ I. Colin Prentice, ${ }^{4}$ Miguel B. Araújo, ${ }^{5,6}$ Nigel W. Arnell, ${ }^{7}$ Alberte Bondeau, ${ }^{1}$ Harald Bugmann, ${ }^{8}$ Timothy R. Carter, ${ }^{9}$ Carlos A. Gracia, ${ }^{10}$ Anne C. de la Vega-Leinert, ${ }^{1}$ Markus Erhard, ${ }^{11}$ Frank Ewert, ${ }^{3}$ Margaret Glendining, ${ }^{12}$ Joanna I. House, ${ }^{4}$ Susanna Kankaanpää, ${ }^{9}$ Richard J. T. Klein, ${ }^{1}$ Sandra Lavorel,,${ }^{13,14}$ Marcus Lindner, ${ }^{15}$ Marc J. Metzger, ${ }^{3}$ Jeannette Meyer, ${ }^{15}$ Timothy D. Mitchell, ${ }^{16}$ Isabelle Reginster, ${ }^{17}$ Mark Rounsevell, ${ }^{17}$ Santi Sabaté, ${ }^{10}$ Stephen Sitch, ${ }^{1}$ Ben Smith, ${ }^{18}$ Jo Smith, ${ }^{19}$ Pete Smith, ${ }^{19}$ Martin T. Sykes, ${ }^{18}$ Kirsten Thonicke, ${ }^{4}$ Wilfried Thuiller, ${ }^{20}$ Gill Tuck, ${ }^{12}$ Sönke Zaehle, ${ }^{1}$ Bärbel Zierl ${ }^{8}$

${ }^{1}$ Potsdam Institute for Climate Impact Research, Potsdam, Germany. ${ }^{2}$ Harvard University, Cambridge, MA, USA. ${ }^{3}$ Wageningen University, Wageningen, The Netherlands. ${ }^{4}$ University of Bristol, Bristol, UK. ${ }^{5}$ University of Oxford, Oxford, UK. ${ }^{6}$ National Museum of Natural Sciences, CSIC, Madrid, Spain. ${ }^{7}$ Tyndall Centre for Climate Change Research, School of Geography, University of Southampton, Southampton, UK. ${ }^{8}$ Eidgenössische Technische Hochschule, Zürich, Switzerland. ${ }^{9}$ Finnish Environment Institute, Helsinki, Finland. ${ }^{10} \mathrm{CREAF}$, University of Barcelona, Barcelona, Spain. ${ }^{11} \mathrm{IMK}-\mathrm{IFU}$, Forschungszentrum Karlsruhe, Garmisch-Partenkirchen, Germany. ${ }^{12}$ Agriculture and the Environment Division, Rothamsted Research, Harpenden, UK. ${ }^{13}$ Laboratoire d'Ecologie Alpine, CNRS, Université Joseph Fourier, Grenoble, France. ${ }^{14}$ Centre d'Ecologie Fonctionnelle et Evolutive, CNRS, Montpellier, France. ${ }^{15}$ European Forest Institute, Joensuu, Finland. ${ }^{16}$ Tyndall Centre for Climate Change Research, University of East Anglia, Norwich, UK. ${ }^{17}$ Université Catholique de Louvain, Louvain-la-Neuve, Belgium. ${ }^{18}$ Lund University, Lund, Sweden. ${ }^{19}$ University of Aberdeen, Aberdeen, UK. ${ }^{20}$ Kirstenbosch Research Center, South African National Biodiversity Institute, Cape Town, South Africa.

*To whom correspondence should be addressed. E-mail: dagmar.schroeter@gmail.com

Impacts of global change will include changes in the supply of ecosystem services vital for human well-being. In a Europe-wide assessment, we investigated ecosystem service supply during the 21st century using a range of ecosystem models and scenarios of climate and land use change. Large changes in climate and land use typically resulted in large changes in ecosystem service supply. Some of these trends may be positive (e.g., increases in forest area and productivity), or offer opportunities (e.g., "surplus land" for agricultural extensification and bioenergy production). However, many changes increase vulnerability due to a decreasing supply of ecosystem services (e.g., declining soil fertility, declining water availability, increasing risk of forest fires), especially in the Mediterranean and mountain regions.

To sustain a future in which the Earth's life support systems are maintained and human needs are met, human activities must first be recognised as an integral component of ecosystems $(1,2)$. Scenarios of global change raise concern about alterations in ecosystem services such as food production and water supply, but the potential trajectories of change, especially at the regional scale, are poorly characterised (3). We investigated the changing supply of ecosystem services in a spatially explicit vulnerability assessment of Europe, using multiple global change scenarios, and a set of ecosystem models. A dialogue with stakeholders from relevant sectors was conducted throughout the study (4).

Our assessment was based on multiple scenarios for major global change drivers (socio-economic factors, atmospheric greenhouse gas concentrations, climate factors, and land use). The scenarios were quantified for Europe (fifteen pre-2004 EU-members, plus Norway and Switzerland, henceforth referred to as EU15+) during the $21^{\text {st }}$ century at $10^{\text {' }} \times 10^{\prime}$ latitude/longitude grid resolution, and for periods ending in 2020, 2050, 2080, relative to baseline conditions in 1990 (5). Socio-economic trends were developed from the global IPCC SRES (Intergovernmental Panel on Climate Change Special Report on Emission Scenarios) storylines B1, B2, A1FI and A2 for EU15+ $(4,6,7)$ (table S1). With this common starting point, socio-economic changes relate directly to climatic changes through greenhouse gas concentrations, and to land use changes through climatic and socio-economic drivers, such as demand for food. Four general circulation models (General Circulation Models, GCMs: HadCM3, NCAR-PCM, CGCM2 and CSIRO2) were used to simulate climatic changes (4). Out of 16 combinations of storylines and GCMs, we selected seven scenarios for interpretation: B1, B2, A1FI, A2 calculated with HadCM3 (variation across storylines, "socio-economic options"), and A2 calculated additionally with three other GCMs (variation across climate models, “climatic uncertainty”, Table 1) (4). 
Temperature change scenarios in Europe vary regionally, but show a clear trend towards warming. The average projected temperature increase in Europe ranged from 2.1 to $4.4^{\circ} \mathrm{C}$ (across storylines) and from 2.7 to $3.4^{\circ} \mathrm{C}$ for the $\mathrm{A} 2$ storyline (across GCMs, Table 1), with the strongest warming consistently in the high latitudes (fig. S1). Seasonal and regional variation of changes in precipitation was considerable. Generally, all scenarios concurred on decreasing precipitation in the south of Europe, particularly in summer (Table 1), and increasing precipitation over much of northern Europe (fig. S2).

Land use scenarios (4) showed little variation based solely upon different GCMs, indicating that socio-economic assumptions had a greater effect on land use than did climatic drivers. The general trends were of reductions in agricultural areas for food production, partly compensated for by increases in bioenergy production and forests, as well as small increases in urban and protected areas (Table 2). In the A ("economic") scenarios the decline in agricultural land was especially pronounced (Fig. 1), mainly owing to assumptions about the role of technological development (8). The land that becomes "surplus" to the requirement of food production would allow balancing the production of other ecosystem services against food production, for example through extensification (9) or bioenergy production (10).

We next examined the changing supply of a number of ecosystem services owing to global change in Europe. The selected services reflect the availability of modelling tools adequate for pan-European assessment, and the aim for a broad range of terrestrial services covering the four servicecategories identified by the Millennium Ecosystem Assessment (1).

The European Commission proposed a target of doubling to $12 \%$ the contribution of renewable energy sources to the EU's total primary energy needs by 2010 (11). Biomass energy will add to this goal. We assessed the potential distribution of 26 bioenergy crops under changing climatic conditions (4). The potential distribution of bioenergy crops increased in northern Europe due to increasing temperatures (Table 2). These potential gains are optimistic, since restricting soil conditions are not taken into account. In contrast, the available choice of bioenergy crops decreased in southern Europe owing to increased drought, unless production systems are adapted (Table 2).

Changes in the provision of water affect humans directly and indirectly, through effects on other ecosystem services. At the global scale, increases in population and consumption alone will reduce water availability $(3,12,13)$. We quantified the implications of population and climate change on water availability in EU15+ using a macro-scale hydrological model (4). In 1995, approximately 193 million people out of a total EU15+ population of 383 million lived under water stress (water availability $<1700 \mathrm{~m}^{3}$ capita $^{-1}$ year $^{-1}$ ) (14). In the absence of climate change these numbers decreased by 2080 where population decreased (scenario B2, Table 1). In contrast, population and climate change increased in the numbers of people living in water-stressed watersheds, and exacerbated water deficiency for many already stressed areas (Table 2), particularly in southern Europe (Fig. 2). Under the A1FI, A2 and B1 scenarios, between 20 and 38\% of the Mediterranean population would be living in watersheds with increased water stress (14\% in B2). In this region, water scarcity would likely be aggravated by higher extractions per capita for irrigation and tourism (15).

Case studies for the Rhine, Rhône and Danube basins, as well as for small Alpine catchments indicated climateinduced changes in the timing of runoff (4). These result from impacts of rising temperatures on snow cover dynamics, which enhanced winter runoff, reduced summer runoff (Table 2), and shifted monthly peak flows by up to two months earlier than at present (16). This reduced water supply at peak demand times and increased the risk of winter floods. Changes in snow cover dynamics directly impact biodiversity at high elevations. Moreover, navigation and hydropower potential would be altered.

In addition to its importance for water supply and biodiversity conservation, snow cover is of course indispensable for winter tourism. The Alpine case studies indicated a rise in the elevation of reliable snow cover from about $1300 \mathrm{~m}$ today to $1500-1750 \mathrm{~m}$ at the end of the $21^{\text {st }}$ century (Table 2) (16). A $300 \mathrm{~m}$ rise of the snow line would reduce the proportion of Swiss ski areas with sufficient snow from currently about $85 \%$ to $63 \%$ (17).

Biodiversity is essential to ecosystem processes in ways that are not yet fully understood (18), and is considered worth protecting in its own right (3). We used a statistical modelling framework to project the distribution of more than 2000 plant and animal species across Europe (4). These simulations do not incorporate effects of land use change, because at the resolution of this study these were confounded with climate effects (19). We therefore present conservative estimates neglecting effects of habitat loss or landscape fragmentation (20). Projections of species loss per grid cell showed changes under all scenarios (Table 2). Mountains and Mediterranean species were disproportionately sensitive to climate change (fig. S3A) $(4,21)$, in agreement with recent observations (22) and projections (23). Under the unrealistic assumption that all species can migrate instantaneously to newly suitable habitat, the relative potential gain of plant species in Mediterranean regions was relatively high because of habitat expansion (fig. S3B). However, unhindered expansion is unlikely because of the concurrent impacts of other drivers such as land use, nitrogen deposition and biotic exchange, especially in the Mediterranean region (20). Flexible management of nature 
reserve areas may conserve species. However, stakeholders pointed out great difficulties in changing existing reserve boundaries under current policies and land ownership restrictions.

To obtain more detailed results on tree species in the Mediterranean region, we used a process-based tree-growth model (4). The simulations corroborated negative effects on vegetation, especially over the long term, owing to increased drought. Furthermore, the area burnt by forest fires increased in this region under all but one scenario (4) (Table 2). The distribution of a number of typical tree species is likely to decrease in the Mediterranean region, e.g. cork oak (Quercus suber), holm oak (Q. ilex), aleppo pine (Pinus halepensis) and maritime pine ( $P$. pinaster). These changes would have implications for the sense of place and cultural identity of the inhabitants, traditional forms of land use and the tourism sector.

We assessed the potential impacts of management and global change on the overall wood production from European forest using an inventory-based model (4). In line with other industrialized areas, but opposed to global trends $(3,24)$, the total European forest area was projected to increase (Table 2). Climate change resulted in increased forest growth (Table 2), especially in northern Europe. The impact of increased summer drought in southern Europe was partly mitigated by higher precipitation in spring and increased water use efficiency in response to rising atmospheric $\mathrm{CO}_{2}$ concentrations. Increasing forest area increased annual wood increment because of a high proportion of young stands. When low wood demand led to less intensive management (B scenarios), forests grew old and less productive, and increment decreased by $10.0 \%$ in the B1 scenario (in B2, afforestation counteracted this effect; Table 2). In general, management had a greater influence on wood production in Europe than climate or land use change. As corroborated by stakeholders, forest management is influenced more strongly by actions outside the forest sector, such as trade and policies, than from within.

The total amount of carbon stored in terrestrial biosphere is an important factor in climate regulation (25). The net carbon land-atmosphere flux is determined by net primary production and carbon losses due to soil heterotrophic respiration, fire, harvesting, and land use change. The aggregate land-atmosphere flux over Europe was estimated using a Dynamic Global Vegetation Model (4). Our results confirm that Europe's terrestrial biosphere currently acts as a net carbon sink (26) (Table 2). Land use change affected this sink positively through decreases in agricultural land and increased afforestation. Furthermore, $\mathrm{CO}_{2}$ fertilization enhanced net primary production. However, soil carbon losses due to warming balanced these effects by 2050, and led to carbon releases by the end of this century. The temperature effect on soil carbon losses is confirmed by recent experimental and modeling studies (27-29) and by separate calculations using a soil carbon model (4). While afforestation led to a net increase in soil organic carbon in forest soils despite the losses due to warming, the total amount of carbon in European soils decreased (Table 2).

Stakeholders were primarily interested in the efficacy of land use changes as a tool for mitigation. We found that the choice of land use is relevant concerning the average yearly carbon uptake and the emission reduction target of the European Union. However, carbon uptake remains small compared to fossil fuel emissions even under the land use change scenario with maximum increase in forest area (Table 2).

Stakeholders from the agricultural sector were interested in soil organic matter content as a key factor in the carbon cycle, and as an indicator of soil fertility. However, their greatest concern was the total amount of land available for farming. This may reflect that current agricultural subsidies disconnect farmers' success from actual ecosystem service supply, such as soil fertility and crop production. In some regions it is therefore questionable whether land that is "surplus" to food demands would readily be open for other uses.

The trends in European change drivers differ from global trends $(3,24)$ in several ways: population increases moderately if at all, the extent of urbanisation is relatively small, forest area increases, and demand for agricultural land decreases. This allows changes in land management that could decrease vulnerability. Problematic trends in the EU15+ are mostly climate-related.

The range of potential impacts in Europe covers socioeconomic options (storylines) and variation among GCMs. For most ecosystem services the A1FI scenario produced the biggest negative impacts, while the B-scenarios seemed preferable. However, a division into either 'economic' (Ascenarios) or 'equitable and environmental' (B-scenarios) does not reflect all societal choices, since sustainability does not forbid economic prosperity (3). The four storylines help explore, but do not contain our optimal future pathway.

Among all European regions, the Mediterranean appeared most vulnerable to global change. Multiple potential impacts were projected, related primarily to increased temperatures and reduced precipitation. The impacts included water shortages, increased risk of forest fires, northward shifts in the distribution of typical tree species, and losses of agricultural potential. Mountain regions also seemed vulnerable because of a rise in the elevation of snow cover and altered river runoff regimes.

The sustained active participation of stakeholders indicated that global change is an issue of concern to them, albeit among many others. The development of adaptation strategies, such as for reduced water use and long-term soil 
preservation, can build on our study but requires further understanding of the interplay between stakeholders and their environment, in the context of local, national and EU-wide constraints and regulations.

\section{References and Notes}

1. Millennium Ecosystem Assessment, Ecosystems and Human Well-being: A Framework for Assessment (Island Press, Washington, 2003).

2. M. Palmer et al., Science 304, 1251 (2004).

3. W. V. Reid et al., Millennium Ecosystem Assessment Synthesis Report (Island Press, Washington, 2005).

4. Materials and methods are available as supporting material on Science Online.

5. The periods represent thirty-year averages; baseline 1990 (mean over 1961-1990), 2020 (mean over 1991-2020), 2050 (mean over 2021-2050) and 2080 (mean over 20512080).

6. The 'economic' A-scenarios represent a world focused on 'material consumption', while the 'environmental' Bscenarios focus on 'sustainability, equity and environment'. The second dimension distinguishes 'globalisation' (dimension 1) versus 'regionalisation' (dimension 2).

7. N. Nakicenovic, R. Swart, Eds., Intergovernmental Panel on Climate Change Special Report on Emissions Scenarios (Cambridge University Press, Cambridge, 2000).

8. F. Ewert, M. D. A. Rounsevell, I. Reginster, M. J. Metzger, R. Leemans, Agric. Ecosyst. Environ. 107, 101 (2005).

9. We refer to extensification as the transition of a land use type with high intensity of use to a lower intensity (e.g. improved grassland to semi-natural cover).

10. M. D. A. Rounsevell, F. Ewert, I. Reginster, R. Leemans, T. R. Carter, Agric. Ecosyst. Environ. 107, 117 (2005).

11. "Energy for the Future: Renewable Sources of Energy White Paper for a Community Strategy and Action Plan” Tech. Report No. 599 (European Communities, 1997).

12. United Nations Environment Programme, "GEO-3: Global Environmental Outlook Report 3” (UNEP, 2002).

13. N. W. Arnell, Global Environ. Change 14, 31 (2004). 14. M. Falkenmark, J. Lundquist, C. Widstrand, Natural Resources Forum 13, 258 (1989).

15. In addition to increasing the number of people served with water in a region, tourists' water consumption has been shown to be far in excess of that of local residents (World Tourism Organisation, $1^{\text {st }}$ International Conference on Climate Change and Tourism, Djerba, Tunisia, 9-11 April, 2003).

16. B. Zierl, H. Bugmann, Water Resour. Res. 41, WO2028 (2005).

17. H. Elsässer, P. Messerli, Mountain Research and Development 21, 335 (2001).

18. D. U. Hooper et al., Ecol. Monogr. 75, 3 (2005).

19. W. Thuiller, Global Change Biol. 10, 2020 (2004).

20. O. E. Sala et al., Science 287, 1770 (2000).

21. W. Thuiller, S. Lavorel, M. B. Araújo, M. T. Sykes, I. C. Prentice, Proc. Natl. Acad. Sci. U.S.A. 102, 8245 (2005).

22. G.-R. Walther et al., Nature 416, 389 (2002).

23. M. Gottfried, H. Pauli, K. Reiter, G. Grabherr, Diversity and Distributions 5, 241 (1995).

24. J. A. Foley et al., Science, 309, 570 (2005).

25. A. D. McGuire et al., Global Biogeochem. Cycles 15, 183 (2001).

26. G. J. Nabuurs et al., Global Change Biol. 9, 152 (2003).

27. C. Fang, P. Smith, J. B. Moncrieff, J. U. Smith, Nature 433, 57 (2005).

28. W. Knorr, I. C. Prentice, J. I. House, E. A. Holland, Nature 433, 298 (2005).

29. E.-D. Schulze, A. Freibauer, Nature 437, 205 (2005).

30. This work was funded by the EU-project ATEAM (Advanced Terrestrial Ecosystem Assessment and Modelling, EVK2-2000-00075). We gratefully acknowledge the enthusiastic support of our EU scientific officer Denis Peter, and our external observers Paul Leadley, Dennis Ojima and Robert Muetzelfeldt. We thank Martin Welp for advice on stakeholder dialogue and our stakeholders for their voluntary collaboration (a full list is found in the Supporting Online Material). Part of this work was carried out while DS was hosted by the Science, Environment and Development Group at the Center for International Development, Harvard University.

\section{Supporting Online Material}

www.sciencemag.org/cgi/contents/full/1115233/DC1

Materials and Methods

Figs. S1 to S3

Tables S1 and S2

References and Notes

24 May 2005; accepted 18 October 2005

Published online 27 October 2005; 10.1126/science.1115233

Include this information when citing this paper. 
Table 1. Summary of the basic socio-economic, atmospheric and climatic drivers based on model outputs forced by SRES scenarios. Population and atmospheric $\mathrm{CO}_{2}$ concentration estimates are for the year 2080. For the climatic indicators 30-year averages 2051-2080 compared to 1961-1990 are shown. The shading highlights the scenarios we focussed on in this study.

\begin{tabular}{|c|c|c|c|c|c|c|}
\hline & & & & ation acr & limate mo & \\
\hline & & Scenarios by 2080 & HadCM3 & $\begin{array}{c}\text { NCAR- } \\
\text { PCM }\end{array}$ & CGCM2 & CSIRO2 \\
\hline & B1 & Population $\left(10^{6}\right)^{\mathrm{a}}$ & 376 & 376 & 376 & 376 \\
\hline & & $\mathrm{CO}_{2}$ concent. (ppm) ${ }^{\mathrm{b}}$ & 518 & 518 & 518 & 518 \\
\hline & & $\Delta$ temperature $\left({ }^{\circ} \mathrm{C}\right)$ & 3.1 & - & - & - \\
\hline & & $\Delta$ precipitation (\%) & & & & \\
\hline & & Europe & 4.8 & - & - & - \\
\hline & & Iberian Peninsula JJA & -17 & - & - & - \\
\hline$\frac{3}{\omega}$ & & Iberian Peninsula DJF & 7 & - & - & - \\
\hline 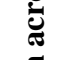 & B2 & Population $\left(10^{6}\right)$ & 346 & 346 & 346 & 346 \\
\hline . & & $\mathrm{CO}_{2}$ concent. (ppm) & 567 & 567 & 567 & 567 \\
\hline & & $\Delta$ temperature $\left({ }^{\circ} \mathrm{C}\right)$ & 2.1 & - & - & - \\
\hline & & $\Delta$ precipitation (\%) & & & & \\
\hline & & Europe & 2.7 & - & - & - \\
\hline & & Iberian Peninsula JJA & -14 & - & - & - \\
\hline & & Iberian Peninsula DJF & 7 & - & - & - \\
\hline
\end{tabular}




\begin{tabular}{|c|c|c|c|c|c|}
\hline \multirow[t]{7}{*}{ A1FI } & Population $\left(10^{6}\right)$ & 376 & 376 & 376 & 376 \\
\hline & $\mathrm{CO}_{2}$ concent. (ppm) & 779 & 779 & 779 & 779 \\
\hline & $\Delta$ temperature $\left({ }^{\circ} \mathrm{C}\right)$ & 4.4 & - & - & - \\
\hline & $\Delta$ precipitation (\%) & & & & \\
\hline & Europe & -0.5 & - & - & - \\
\hline & Iberian Peninsula JJA & -27 & - & - & - \\
\hline & Iberian Peninsula DJF & 2 & - & - & - \\
\hline \multirow[t]{7}{*}{ A2 } & Population $\left(10^{6}\right)$ & 419 & 419 & 419 & 419 \\
\hline & $\mathrm{CO}_{2}$ concent. (ppm) & 709 & 709 & 709 & 709 \\
\hline & $\Delta$ temperature $\left({ }^{\circ} \mathrm{C}\right)$ & 2.8 & 2.7 & 3.4 & 2.7 \\
\hline & $\Delta$ precipitation (\%) & & & & \\
\hline & Europe & 0.5 & 2.3 & 0.0 & -0.6 \\
\hline & Iberian Peninsula JJA & -22 & -18 & -26 & -19 \\
\hline & Iberian Peninsula DJF & 10 & 0 & 1 & -3 \\
\hline
\end{tabular}

$\overline{{ }^{a}}$ The EU15+ population in 1990 was 376 million people.

${ }^{\mathrm{b}}$ Please note that the GCMs were forced with these concentrations plus $\mathrm{CO}_{2}$-equivalents accounting for the other greenhouse gases. The atmospheric $\mathrm{CO}_{2}$ concentration in 1990 was 354 ppmv.

${ }^{\mathrm{c}}$ Precipitation changes (\%) on the Iberian Peninsula. JJA = Summer (June, July, August), DJF = Winter (December, January, February). 
Table 2. Summary of land use drivers and global change impacts for Europe, time period 2080 compared to baseline (1990), if not noted otherwise (4).

\begin{tabular}{|c|c|c|c|c|c|c|c|}
\hline $\begin{array}{r}\text { Storyline } \\
\text { GCM }\end{array}$ & $\begin{array}{l}\text { B1 } \\
\text { HadCM3 }\end{array}$ & $\begin{array}{l}\text { B2 } \\
\text { HadCM3 }\end{array}$ & $\begin{array}{l}\text { A1FI } \\
\text { HadCM3 }\end{array}$ & $\begin{array}{l}\text { A2 } \\
\text { HadCM3 }\end{array}$ & $\begin{array}{l}\text { A2 } \\
\text { NCAR- } \\
\text { PCM }\end{array}$ & $\begin{array}{l}\text { A2 } \\
\text { CGCM2 }\end{array}$ & $\begin{array}{l}\text { A2 } \\
\text { CSIRO2 }\end{array}$ \\
\hline \multirow{2}{*}{\multicolumn{8}{|c|}{$\begin{array}{l}\text { Land use model outputs forced by climate, } \mathrm{CO}_{2} \\
\text { and interpretations of SRES storylines }\end{array}$}} \\
\hline & \multicolumn{7}{|c|}{ Land use change $(\%)^{\mathrm{a}}$} \\
\hline Cropland (for food production) & -7.0 & -6.4 & -10.7 & -10.4 & -10.6 & -10.7 & -10.6 \\
\hline Grassland (for livestock) & -1.1 & -6.7 & -8.7 & -10.0 & -10.1 & -10.2 & -10.0 \\
\hline Forest & 3.5 & 5.6 & 0.8 & 0.7 & 1.0 & 1.0 & 1.2 \\
\hline Urban & 0.05 & 0.06 & 0.09 & 0.08 & 0.07 & 0.07 & 0.07 \\
\hline Bioenergy production & 3.4 & 7.4 & 8.7 & 8.7 & 9.1 & 8.6 & 8.6 \\
\hline Protected & 6.1 & 6.1 & 6.1 & 6.1 & 6.1 & 6.1 & 6.1 \\
\hline Surplus & 1.1 & 0.0 & 9.8 & 10.9 & 10.5 & 11.2 & 10.8 \\
\hline \multicolumn{8}{|l|}{ Impacts as estimated by ecosystem models } \\
\hline \multicolumn{8}{|l|}{$\Delta$ pot. distribution of bioenergy crops (\%) } \\
\hline Overall & 3 & 4 & 1 & 3 & 6 & 7 & 5 \\
\hline Latitude 35-45 & -7 & -6 & -13 & -8 & -1 & -3 & -2 \\
\hline Latitude 45-55 & -1 & 0 & -6 & -2 & 4 & 8 & -6 \\
\hline Latitude 55-65 & 12 & 13 & 12 & 13 & 11 & 14 & 15 \\
\hline Latitude 65-71 & 18 & 22 & 32 & 23 & 19 & 16 & 34 \\
\hline Additional people living under water stress $\left(10^{6}\right)^{c}$ & 44.3 & 25.8 & 44.3 & 15.7 & 7.5 & 11.7 & 5.8 \\
\hline People living under increased water stress $\left(10^{6}\right)^{d}$ & 31.0 & 38.2 & 45.7 & 35.6 & 18.4 & 69.6 & 25.4 \\
\hline$\Delta$ Alpine summer runoff $(\%)^{\mathrm{e}}$ & -24 & -23 & -46 & -34 & -12 & -27 & -20 \\
\hline$\Delta$ Elevation of reliable snow cover $(\mathrm{m})^{\mathrm{e}}$ & 230 & 180 & 450 & 310 & 200 & 230 & 390 \\
\hline Species loss per grid cell, min. to max. $(\%)^{\mathrm{f}}$ & -7 to -58 & -8 to -53 & -8 to -59 & -8 to -55 & & & \\
\hline$\Delta$ Area burnt, Iberian Peninsula (\%) & 112 & 57 & 80 & 55 & -1 & 37 & 8 \\
\hline$\Delta$ Wood increment (\%) & -10.0 & 9.7 & 3.8 & 4.4 & 2.9 & 2.9 & 6.2 \\
\hline Cumulative carbon balance (Pg C) $)^{\mathrm{g}}$ & 2.2 & 2.4 & 1.8 & 3.0 & 4.9 & 4.1 & 3.7 \\
\hline Average carbon flux (\% of emissions) ${ }^{\mathrm{h}}$ & 2.5 & 2.7 & 2.1 & 3.5 & 5.5 & 4.7 & 4.2 \\
\hline \multicolumn{8}{|l|}{$\Delta$ Soil organic carbon $(\operatorname{Pg} C)^{\mathrm{i}}$} \\
\hline Total & -0.1 & -0.9 & -4.1 & -4.4 & -4.3 & -4.5 & -4.8 \\
\hline Cropland & -4.3 & -4.3 & -5.9 & -5.6 & -5.4 & -5.5 & -5.8 \\
\hline Grassland & 1.5 & -1.2 & -2.2 & -2.7 & -2.7 & -2.7 & -2.8 \\
\hline Forest & 2.8 & 3.6 & 1.0 & 1.1 & 1.3 & 1.3 & 0.7 \\
\hline
\end{tabular}

a Baseline areas (\% of EU15+): cropland 23.0\%, grassland 17.2\%, forest 31.0\%, urban 1.5\%, other (shrubland, barren land, wetland, inland waters, sea, permanent ice and snow) $27.3 \%$. For all scenarios it is assumed that $20 \%$ of the area of Europe will become designated as "protected" by 2080. This was based on a judgement made from past and current increases in protectedareas coverage in Europe, the latter being due to member-state responses to the need for implementation of the NATURA 2000 network. Whilst this target was the same for all scenarios, it was assumed that it would be reached for different reasons: the economic scenarios require areas for recreation for a richer population, whereas the environmental scenarios require areas designated for conservation purposes (see also Tab. S1 and S2). "Surplus" is land that is left over when the demand for all land use types is satisfied.

b Change in potential distribution of 26 bioenergy crops (\% land area) due to climate change. The estimates do not take soil conditions into account. 
c Additional people (millions) living in stressed watersheds due to climate change (compared with hypothetical case of no climate change). Water-related resource problems are likely when water availability falls below the threshold of $1700 \mathrm{~m} 3$ capita1year1 (14).

d People (millions) living in already water-stressed watersheds (less than 1700 m3capita-1year-1, see above), where climate change reduces water availability further by more than $10 \%$.

e Average of five Alpine case studies.

f 2050 compared to baseline (1990). The range of minimum (full instantaneous dispersal) to maximum (zero dispersal) loss is shown. Plants, mammals, reptiles, amphibians, and breeding birds were considered. Please note that this indicator records only losses from a specific grid cell and does not take potential gains into account. The indicator does not make a statement about potential losses of the species from Europe, or about extinction.

g Cumulative land-atmosphere carbon flux between 1990 and 2080, positive values denote fluxes to land.

h Average yearly land-atmosphere flux (1990-2080) relative to EU15+ CO2-emissions in 1990.

i Change in cumulative soil organic carbon content in mineral soil down to $30 \mathrm{~cm}$

depth. 
Fig. 1. Change in cropland area (for food production) by 2080 compared to baseline (\% of EU15+ area) for the four storylines (A1 is A1FI, A2, B1 and B2) with climate calculated by HadCM3.

Fig. 2. Stress status of water basins by 2080 considering climate change and population growth, compared to the hypothetical case of no climate change. Stressed water basins have less than $1700 \mathrm{~m}^{3}$ capita $^{-1}$ year $^{-1}(14)$. Only water basins that affect the EU15+ are shown. "No significant change" means changes in average annual runoff for these stressed watersheds are less than $10 \%$. Panels marked A1, A2, B1, B2 show the four storylines (A1 is A1FI) based on HadCM3 climate (2051-2080) and respective population sizes. Panels marked HadCM3, CSIRO2, CGCM2 and PCM show the four GCMs (2051-2080; PCM is NCAR-PCM) and A2 population size. 

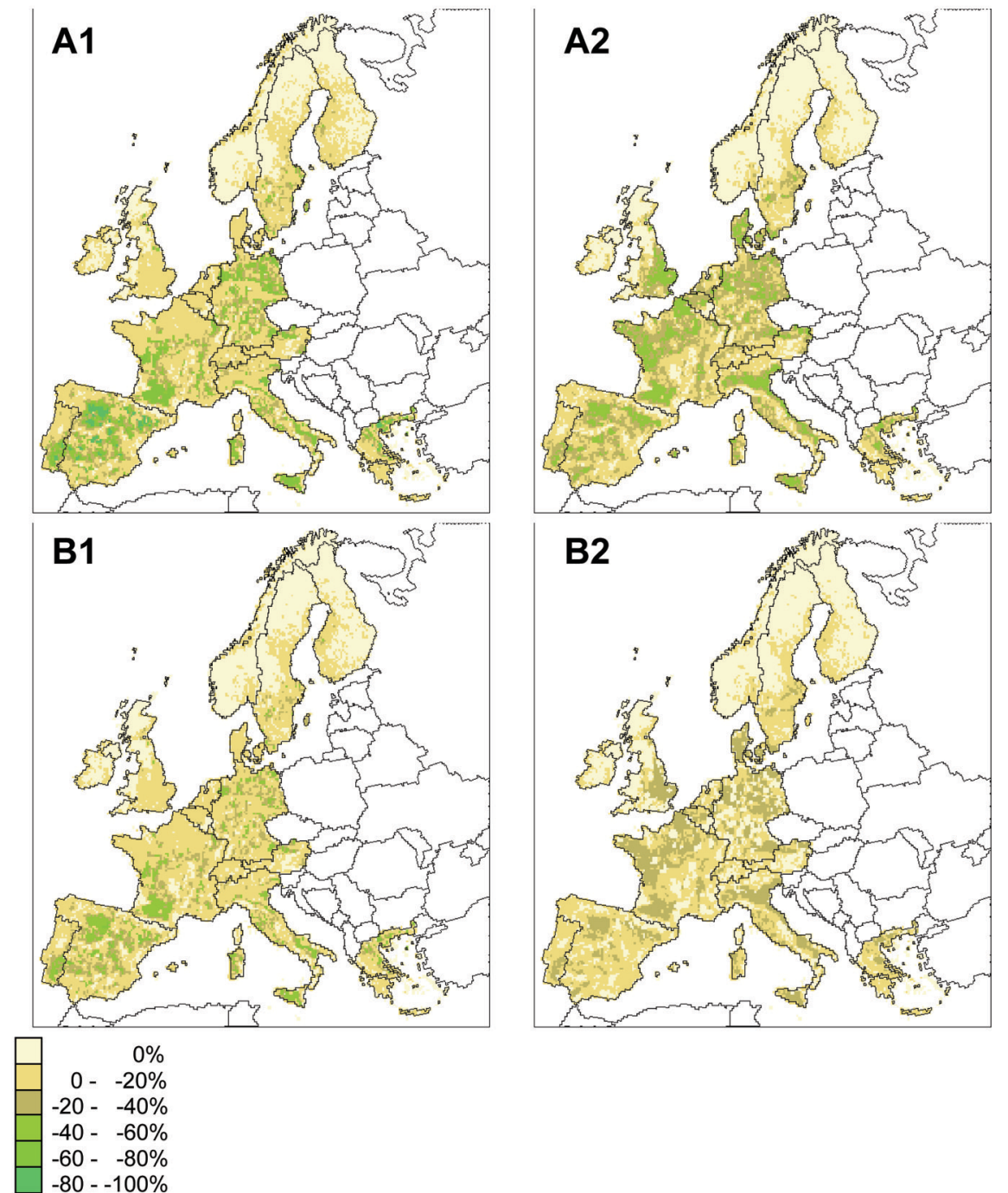

$0 \%$
$0--20 \%$
$-20--40 \%$
$-40--60 \%$
$-60--80 \%$
$-80--100 \%$


